\title{
Prenatal and postnatal bisphenol A exposure and social impairment in 4-year- old children
}

\author{
Youn-Hee Lim ${ }^{1,2}$, Sanghyuk Bae ${ }^{3}$, Bung-Nyun Kim ${ }^{4}$, Choong Ho Shin ${ }^{5}$, Young Ah Lee ${ }^{5}$, Johanna Inhyang Kim ${ }^{4}$ \\ and Yun-Chul Hong ${ }^{1,2,6^{*}}$
}

\begin{abstract}
Background: Prenatal and postnatal exposure to bisphenol A (BPA) may affect early brain development. Rodent studies suggest that prenatal and postnatal neurodevelopmental toxicity from BPA exposure may manifest as social deficits in offspring. We investigated the association between prenatal and postnatal exposure to BPA and social impairments in a sample of 4-year-old children.

Methods: We recruited second-trimester pregnant women between 2008 and 2011, and measured their creatinineadjusted prenatal urine BPA levels. In 2014-2015, a subset of 4-year-old children born to these women underwent neurobehavioral assessment and physical examination. We collected urine and blood from the children and assessed social impairments, including deficits in social interaction, social communication, and other behavior patterns using the Korean version of the Social Communication Questionnaire (K-SCQ) $(n=304)$. We examined social impairments associated with prenatal exposure at mid-term pregnancy and postnatal exposure to BPA at 4 years of age, using linear and piecewise linear regression models.
\end{abstract}

Results: The relationship between prenatal BPA exposure and social communication was non-linear and statistically significant at or above the flexion point for BPA levels of $3.0 \mathrm{\mu g} / \mathrm{g}$ creatinine in girls $(58.4 \%, 95 \%$ confidence interval [Cl], 6.5\% to 135.8\%). Each 2-fold increase in postnatal BPA exposure was significantly associated with an $11.8 \%(95 \% \mathrm{Cl}$, $0.6 \%$ to $24.3 \%$ ) increase in impairment in social communication in 4-year old girls, as indicated by the linear regression model.

Conclusion: Prenatal and postnatal BPA exposure is associated with social impairment at 4 years of age, particularly in girls.

Keywords: Bisphenol A, Childhood exposure, Children's environmental health, Prenatal exposure, Social impairment

\section{Background}

Bisphenol A (BPA) is an organic synthetic compound used to make plastics and epoxy resins. Widespread use of BPA results in contamination in every individual [1-4]. In particular, BPA has been detected in the urine of pregnant women and children [5-11]. The health effects of prenatal and postnatal BPA exposure are reflected in children's behavior [12-15], and as anxiety and depression [16]. However, few studies have examined social impairments

\footnotetext{
* Correspondence: ychong1@snu.ac.kr

'Institute of Environmental Medicine, Seoul National University Medical

Research Center, Seoul, Republic of Korea

${ }^{2}$ Environmental Health Center, Seoul National University College of Medicine,

Seoul, Republic of Korea

Full list of author information is available at the end of the article
}

associated with prenatal and postnatal exposure to BPA. Rodent studies indicate that exposure to low doses of BPA in utero have immediate and enduring transgenerational effects on social interactions and recognition [17, 18]. However, cohort studies examining prenatal exposure to BPA have not found significant associations with social impairments in children 4-9 years of age [19, 20].

Social impairment is defined as a lack of involvement in relationships with others. It typically occurs with neurological development problems such as autism spectrum disorders (ASDs). The European Union has expressed concern regarding data [21] indicating that exposure to endocrine disruptors may contribute to neurobehavioral deficits and disease, which cost more than 
$€ 150$ billion per year in Europe. In an effort to better control endocrine-disrupting chemicals, the European Food Safety Authority reduced the safety level of BPA from a combination of sources (e.g., diet, dust, cosmetics, and thermal paper) from $50 \mu \mathrm{g} / \mathrm{kg}$ of body weight/day to $4 \mu \mathrm{g} / \mathrm{kg}$ in 2015 [22]. However, uncertainty persists regarding the transgenerational effects of low-dose exposure to BPA on neurodevelopmental health, as assessed by toxicological testing [23]. Moreover, a non-monotonic dose-response relationship between low-dose endocrine disruptors and measures of behavioral and learning problems complicates our understanding of the biological effects of BPA [24-27]. In addition, sex- and time-specific effects on neurodevelopment or behavioral outcomes following BPA exposure have been reported in animal studies [28-32]; however, the traits that are most sensitive to BPA in humans have not been fully elucidated [12, 14-16]. Therefore, birth cohort studies are needed to confirm the time- and gender-dependent nature of BPA exposure by examining the dose-response relationship between prenatal and postnatal exposure to low-dose BPA and social impairment in girls and boys. In the present study, we used an ongoing cohort of 4-year-old children to examine social impairments associated with prenatal and postnatal exposure to BPA, using linear and non-linear regression models to examine overall and threshold BPA effects. In addition, we examined gender-specific effects on social impairment.

\section{Methods}

\section{Population}

The present study, the Environment and Development of Children (EDC) Study, is a prospective cohort study of the growth and development of children. The participants are children whose mothers participated in another study of birth outcomes, the Congenital Anomaly Study (CAS). The CAS cohort consisted of pregnant women who received prenatal care at 1 of 8 hospitals in the metropolitan areas of Seoul and Incheon, the Republic of Korea. The study enrolled 13,484 women during the second trimester of pregnancy and 11,085 of these women remained in the study until they gave birth between August 2008 and July 2011. At the time of enrollment, blood and urine samples were collected after more than $8 \mathrm{~h}$ of fasting and a questionnaire regarding demographics and lifestyle was administered by trained nurses. The CAS cohort included 115 children with congenital anomalies. After excluding mothers having children with congenital anomalies $(n=115)$ and those with invalid addresses $(n=218), 10,752$ mothers were target participants for a new birth cohort comprising the EDC study (Additional file 1: Figure S1(a)).

We determined that a sample size of 610 (effect size 0.017 [33], alpha 0.05 , power 0.90 ) would sufficiently examine the association between BPA exposure and children's growth variables such as body mass index (BMI); we inflated the sample size to 645 children in order to allow for an $\sim 5 \%$ drop-out rate. Between 2012 and 2015, we contacted 2085 mothers chosen randomly from the 10,752 target participants, until enrolling 645 motherchild pairs (615 mothers, including 30 multiple births) in the EDC study (response rate, 31\%). We conducted follow-ups when the children were approximately 4 years of age, between March 2013 and December 2015 (Additional file 1: Figure S1(b)). The children underwent health examinations at the Seoul National University Hospital located in Jongno-gu, Seoul, Republic of Korea. The mothers' depressive symptoms and children's dietary habits were assessed using the Center for Epidemiologic Studies Depression (CES-D) [34] and food frequency questionnaires (FFQs) [35], respectively.

Neurobehavioral tests for social impairments and attention deficit hyperactivity disorder were administered in 2014 to the 4-year-old children. Therefore, social impairments were measured only in the 425 children who were followed up since 2014, but not in the 220 children who were followed up in 2013. Social impairments were assessed using the Korean version of the Social Communication Questionnaire (K-SCQ). However, 12 children did not complete this questionnaire; therefore, 413 children had valid social impairment scores at 4 years of age.

At the follow-up examination, urine and blood sample collections, as well as physical examinations, were conducted after the children had fasted for more than $8 \mathrm{~h}$. After excluding those without maternal $(n=93)$ or child $(n=1)$ BPA measurements and those with gestational ages $<36$ weeks $(n=13)$ or unknown gestational ages $(n=2)$, 304 mother-child pairs were included in the present analyses. We obtained informed consent from all participants and the study protocol was approved by the Institutional Review Board at the College of Medicine, Seoul National University (IRB No. 1201-010-392).

\section{Social impairment}

Symptoms of social impairment were measured using the validated K-SCQ [36, 37], which was completed by parents or caregivers. The K-SCQ has previously been used to screen for social impairments in children [38]. The K-SCQ consists of 40 items scored as " 1 " if the child has the item-specific social impairment symptom or "0" if that symptom is not present. The K-SCQ items can be divided into 3 subcategories of social impairments: social interaction, social communication, and behavior patterns (including restricted, repetitive, and stereotyped patterns of behavior [36]. Total scores and sub-scores for social impairment were calculated by summing the response scores for all applicable items. Higher total measure scores indicate a greater number of social impairment 
symptoms. Although total scores above a cutoff of 15 suggest that the individual is likely to have ASD [38], we could not investigate the relationship between ASD and BPA exposure because none of the children in the study had a score greater than 15 .

\section{Exposure}

Maternal spot urine samples were collected in conical tubes (SPL Lifesciences, Pocheon, Gyunggi-do, Republic of Korea) during the second trimester of pregnancy, between 14 and 27 weeks (mean of 20 weeks) of gestation. Children's urine samples were collected after $8 \mathrm{~h}$ of fasting. The samples were sent to the laboratory (Seegene Medical Foundation, Seoul, Republic of Korea) and stored at $-20{ }^{\circ} \mathrm{C}$. We measured the total concentrations (free and conjugated species) of urinary BPA. Urine samples were treated with $\beta$-glucuronidase/sulfatase to hydrolyze conjugated BPA species [13]. BPA concentrations were quantified using high-performance liquid chromatography-tandem mass spectrometry (Agilent 6410 Triple Quad LCMS; Agilent, Santa Clara, CA, USA), as described previously [39, 40]. Standard solutions with BPA concentrations of 50, 25, 12.5, 6.25, 3.125 , and $1.5625 \mu \mathrm{g} / \mathrm{L}$ were prepared and analyzed along with blanks to determine the standard calibration curve $\left(r^{2}>0.999\right)$. When the measured sample concentration was above the maximum concentration of the standard solution, the extract was diluted in water (1:1), separated into halves, and analyzed. One portion was subject to re-analysis if the detected concentration was not within $20 \%$ of the standard calibration curve. The lower limit of detection (LOD) for BPA ranged from 0.031 to $0.212 \mu \mathrm{g} / \mathrm{L}$, depending on the batch used. We used an LOD of $0.212 \mu \mathrm{g} / \mathrm{L}$ divided by the square root of 2. We used creatinine-adjusted BPA concentrations in units of $\mu \mathrm{g} / \mathrm{g}$ of creatinine in analyses to assess variations in urine concentrations of BPA [1]. Postnatal urinary BPA concentrations at the time of follow-up (approximately age 4) were measured using the same method used to measure maternal urinary BPA. Prenatal and postnatal BPA exposures were natural log-transformed for normality.

\section{Covariates}

Potential covariates for inclusion in the statistical models were selected a priori, following a literature review [12, 13, 41]. Prenatal information was obtained using questionnaires at the time of recruitment; variables of interest included maternal age (years), gestational age (weeks), smoking (yes or no), drinking alcohol during pregnancy (yes or no), educational attainment ( $\leq$ or $>$ than high school), parity (first vs. second or later child), and CES-D scores (0-60 points). Children's characteristics such as age (months), gender, BMI $\left(\mathrm{kg} / \mathrm{m}^{2}\right)$, birth weight $(\mathrm{kg})$, child-care (home, daycare, or other), exposure to second hand tobacco smoke (yes or no), and infant feeding type (breast feeding, bottle feeding, or mixed) were obtained at the follow-up visit. From various dietary habits queried by the FFQs, we selected those that were likely to be associated with BPA levels ( $P$-value $<0.1)$, including canned food or drinks $(<$ or $\geq 1$ per week), instant rice ( $<$ or $\geq 1$ per week), and use of plastic dishes in the microwave oven (yes or no).

Covariates were first determined by searching for variables that reduced the Akaike information criterion (AIC) [42] in the model by $>10 \%$, compared to the base model (prenatal and postnatal BPAs were independent variables in the base model). Second, we selected variables that were significantly associated with total SCQ scores $(P$-value $<0.05)$ after controlling for other covariates. In the final model, covariates included gender, parity, maternal education, birth weight, and use of plastic dishes in the microwave oven. We also controlled for prenatal and postnatal levels of urinary BPA.

\section{Statistical analyses}

Generalized additive models (GAMs) were constructed to investigate the relationship between prenatal and postnatal BPA concentrations and social impairments at age 4. BPA has non-monotonic effects [41, 43]; therefore, we constructed 2 models, including 1 with a linear BPA term and another spline model for BPA exposure (4 degrees of freedom). When the shape of the association in GAMs looked nonlinear, we compared the AIC of linear and spline models to select a better-fit model for a given set of data. We also calculated the difference of deviances for the fitted models and tested statistical significance of the difference, which followed a chi-square distribution.

After visualizing the relationship between BPA exposure and social impairments, we estimated the contributions of BPA to the linear and piecewise linear regression models. First, to estimate the overall linear effects of BPA on social impairments, we constructed regression models for BPA exposure and social impairments. Second, we estimated prenatal and postnatal BPA effects at concentrations that were either less than, or equal to/greater than, threshold BPA concentrations, using piecewise linear regression models and the threshpt function in the HEAT package [44] of $\mathrm{R}$ software ( $\mathrm{R}$ Development Core Team, https://cran.r-project.org/). Piecewise linear regression analysis has been used to determine flexion points in non-linear relationships $[41,45,46]$ using AIC as a measure of the relative quality of a statistical model for a given set of data. We modeled scores on the K-SCQ as a Poisson distribution and estimated the effects of BPA on the total and subcategory scores for social impairments (social 
interaction, social communication, and behavior patterns). All models were controlled for gender, parity, maternal education, birth weight, use of plastic dishes in the microwave oven, and prenatal or postnatal levels of urinary BPA. To examine gender differences in our analyses, we stratified our samples by children's gender.

In our sensitivity analysis, we examined the association between prenatal and postnatal concentrations of BPA and children's social impairments at age 4, using BPA concentrations $(\mu \mathrm{g} / \mathrm{L})$ unadjusted for creatinine, and using the same covariates as the main analyses. Instead of directly adjusting for BPA concentrations, the urinary creatinine levels of the mothers and children were included in the model. Finally, we compared percentage changes in SCQ total scores associated with prenatal and postnatal BPA, with or without adjusting for covariates that were excluded in the final model; the covariates included maternal age, gestational age, smoking during pregnancy, drinking alcohol during pregnancy, mother's depression, child's age, infant feeding type, second hand smoke, place of childcare, canned food or drink, and instant rice. All analyses were conducted using SAS (v9.4; Cary, NC, USA) and the R software package (v3.2.1). Two-tailed $P$ values $<0.05$ were considered statistically significant.

\section{Results}

Characteristics of mothers $(n=615)$ included in the present EDC study were different from excluded mothers $(n=10,137)$ in the CAS cohort; differences in the EDC cohort included that the mothers were older (31.2 years vs. 30.6 years for included and excluded mothers, respectively), children were born at an earlier gestational age ( 39.2 weeks vs. 39.3 weeks), there were more twin or triplets (3.9\% vs. $1.7 \%)$, and there were more current or past smokers (45.6 vs. 41.3) (Additional file 1: Table S1). Characteristics including maternal age, prenatal BPA levels, and K-SCQ scores of the children in the present study $(N=304)$ were similar to those of the excluded children $(N=341)$. However, the included children were slightly younger (47.7 vs. 48.0 months; $P=0.0270$ ) and had lower creatinine-adjusted BPA levels at 4 years of age (4.9 vs. $5.7 \mu \mathrm{g} / \mathrm{g}$ creatinine; $P=0.0006)$ compared to the excluded children (Additional file 1: Table S1).

The mean age of the 304 mothers was 31.2 years, and $82.9 \%$ of the mothers had higher than a high school education. The children included $52.6 \%$ boys, $63.8 \%$ of which were the first child in the family. Only $52.1 \%$ of the girls were the first child in the family. The mean score for depressive symptoms was 11.4. The mean creatinine-adjusted BPA exposure at the midterm of the pregnancy was $2.0 \mu \mathrm{g} / \mathrm{g}$ creatinine (Table 1). Approximately one-quarter of the children were exposed to second hand tobacco smoke. Among dietary habits, only canned food or drink consumption was higher in boys than in girls. The mean creatinine-adjusted BPA level in the 4-year-old children was $4.9 \mu \mathrm{g} / \mathrm{g}$ creatinine. A greater total number of social impairment symptoms were observed in the boys compared to girls. This gender difference was statistically significant (5.0 vs. 3.6, respectively; $P=0.0001$ ). The difference was predominantly attributed to the behavior patterns subcategory (1.7 vs. 1.1 in boys and girls, respectively) (Table 2).

Table 1 Characteristics of participants' mothers $(N=304)$

\begin{tabular}{|c|c|c|c|c|}
\hline \multirow[t]{2}{*}{ Variables } & \multicolumn{3}{|c|}{ Mean \pm SD, N (\%) } & \multirow[t]{2}{*}{$P$-value } \\
\hline & Overall & Boys $(n=160)$ & Girls $(n=144)$ & \\
\hline \multicolumn{5}{|l|}{ Maternal information } \\
\hline Mother's age (years) & $31.2 \pm 3.6$ & $31.4 \pm 3.7$ & $31.0 \pm 3.4$ & 0.3873 \\
\hline Gestational age (weeks) & $39.2 \pm 1.2$ & $39.2 \pm 1.2$ & $39.2 \pm 1.2$ & 0.9349 \\
\hline Smoking during pregnancy & $7(2.4)$ & $4(2.6)$ & $3(2.2)$ & 1.0000 \\
\hline Drinking alcohol during pregnancy & $28(9.7)$ & $21(13.6)$ & $7(5.2)$ & 0.0172 \\
\hline Mother's education & & & & 0.4490 \\
\hline$>$ High school & $252(82.9)$ & $130(81.3)$ & $122(84.7)$ & \\
\hline$\leq$ High school & $52(17.1)$ & $30(18.8)$ & $22(15.3)$ & \\
\hline Parity & & & & $<.0001$ \\
\hline First child & $177(58.2)$ & $102(63.8)$ & $75(52.1)$ & \\
\hline Second + & $127(41.8)$ & $58(36.3)$ & $69(47.9)$ & \\
\hline Depression score (0-60) & $11.4 \pm 7.9$ & $11.2 \pm 8.1$ & $11.5 \pm 7.6$ & 0.8108 \\
\hline Creatinine $(\mu \mathrm{g} / \mathrm{L})$ & $87.9 \pm 50.3$ & $88.0 \pm 49.2$ & $87.7 \pm 51.7$ & 0.9531 \\
\hline Creatinine-adjusted prenatal BPA ( $\mu \mathrm{g} / \mathrm{g}$ creatinine) & $2.0 \pm 2.1$ & $2.3 \pm 2.3$ & $1.6 \pm 1.7$ & 0.0088 \\
\hline
\end{tabular}


Table 2 Characteristics of children in the present study $(N=304)$

\begin{tabular}{|c|c|c|c|c|}
\hline \multirow[t]{2}{*}{ Variables } & \multicolumn{3}{|c|}{ Mean \pm SD, N (\%) } & \multirow[t]{2}{*}{$P$-value } \\
\hline & Overall & Boys $(n=160)$ & Girls $(n=144)$ & \\
\hline Child's age (months) & $47.7 \pm 2.1$ & $47.7 \pm 2.0$ & $47.8 \pm 2.1$ & 0.4569 \\
\hline Body mass index & $15.7 \pm 1.3$ & $15.8 \pm 1.2$ & $15.7 \pm 1.3$ & 0.4508 \\
\hline Birth weight (kg) & $3.3 \pm 0.4$ & $3.3 \pm 0.4$ & $3.2 \pm 0.4$ & 0.0274 \\
\hline Feeding & & & & 0.8972 \\
\hline Breast feeding only & $77(34.5)$ & $38(31.7)$ & 39 (37.9) & \\
\hline Breast and bottle feeding & $124(55.6)$ & $73(60.8)$ & $51(49.5)$ & \\
\hline Bottle feeding only & $22(9.9)$ & $9(7.5)$ & $13(12.6)$ & \\
\hline Place of childcare & & & & 0.5199 \\
\hline Home & $177(65.8)$ & $94(64.0)$ & $83(68.0)$ & \\
\hline Daycare or other & $92(34.2)$ & $53(36.1)$ & $39(32.0)$ & \\
\hline Second hand smoke exposure & & & & 0.0477 \\
\hline No & $221(72.7)$ & $115(71.9)$ & $106(73.6)$ & \\
\hline Yes & $83(27.3)$ & $45(28.1)$ & $38(26.4)$ & \\
\hline Canned food or drink & & & & 0.0011 \\
\hline$<1$ per week & $259(85.2)$ & $126(78.8)$ & $133(92.4)$ & \\
\hline$\geq 1$ per week & $45(14.8)$ & $34(21.3)$ & $11(7.6)$ & \\
\hline Instant rice & & & & 0.1246 \\
\hline$<1$ per week & $300(98.7)$ & $156(97.5)$ & $144(100.0)$ & \\
\hline$\geq 1$ per week & $4(1.3)$ & $4(2.5)$ & & \\
\hline Use of plastic dishes in the microwave oven & & & & 0.8831 \\
\hline No & $247(81.3)$ & $129(80.6)$ & $118(81.9)$ & \\
\hline Yes & $57(18.8)$ & $31(19.4)$ & $26(18.1)$ & \\
\hline BPA at 4 years of age $(\mu \mathrm{g} / \mathrm{L})$ & $3.2 \pm 5.0$ & $3.2 \pm 3.1$ & $3.3 \pm 6.6$ & 0.8144 \\
\hline Creatinine $(\mu \mathrm{g} / \mathrm{L})$ & $72.1 \pm 34.9$ & $74.9 \pm 35.3$ & $69.1 \pm 34.3$ & 0.1483 \\
\hline Creatinine-adjusted BPA at 4 years of age ( $\mu \mathrm{g} / \mathrm{g}$ creatinine) & $4.9 \pm 10.8$ & $4.3 \pm 3.6$ & $5.5 \pm 15.3$ & 0.3366 \\
\hline K-SCQ- Total & $4.3 \pm 3.1$ & $5.0 \pm 3.2$ & $3.6 \pm 2.7$ & 0.0001 \\
\hline K-SCQ- Social interaction & $1.1 \pm 1.2$ & $1.2 \pm 1.3$ & $0.9 \pm 1.0$ & 0.0083 \\
\hline K-SCQ- Communication & $1.7 \pm 1.4$ & $1.8 \pm 1.4$ & $1.6 \pm 1.3$ & 0.0956 \\
\hline K-SCQ- Behavior Patterns & $1.4 \pm 1.7$ & $1.7 \pm 1.7$ & $1.1 \pm 1.5$ & 0.0014 \\
\hline
\end{tabular}

Abbreviations: SD standard deviation, BPA bisphenol A, K-SCQ Korean version of the Social Communication Questionnaire

Creatinine adjusted prenatal and postnatal BPA concentrations were not significantly correlated (Pearson's correlation $=0.01136)$.

Figure 1(a) and (b) show the associations between prenatal and postnatal BPA and K-SCQ scores, respectively. The regression curve deviates from a straight line and has a flexion point at around $3.0 \mu \mathrm{g} / \mathrm{g}$ creatinine of prenatal BPA at the mid-term of pregnancy (Fig. 1(a)). AIC in the spline model with 4 degrees of freedom was slightly smaller compared to the linear model (1495 for the spline model vs. 1497 for the linear model), suggesting that the spline model is a better fit to assess prenatal BPA and social impairments. The difference in deviance was statistically significant $(P=0.0284)$. Furthermore, $18 \%$ of mothers (55 of 304 ) had values above this level of $3.0 \mu \mathrm{g} / \mathrm{g}$ creatinine, which is 1.5 times greater than the mean prenatal BPA concentration in our sample. The maximum BPA level was $13.0 \mu \mathrm{g} / \mathrm{g}$ creatinine. The assumption of linearity was met for the association between social impairments and postnatal BPA levels at 4 years of age (Fig. 1(b)). AIC values were 1498 for the spline model with 4 degrees of freedom and 1495 for the linear model, suggesting that the linear model is a better fit for our data regarding the association between postnatal BPA and social impairment. Difference of deviance was not statistically significant $(P=0.2391)$.

Table 3 presents estimations of linear relationships between prenatal and postnatal BPA exposure and the total and subcategory scores for social impairments. We did 

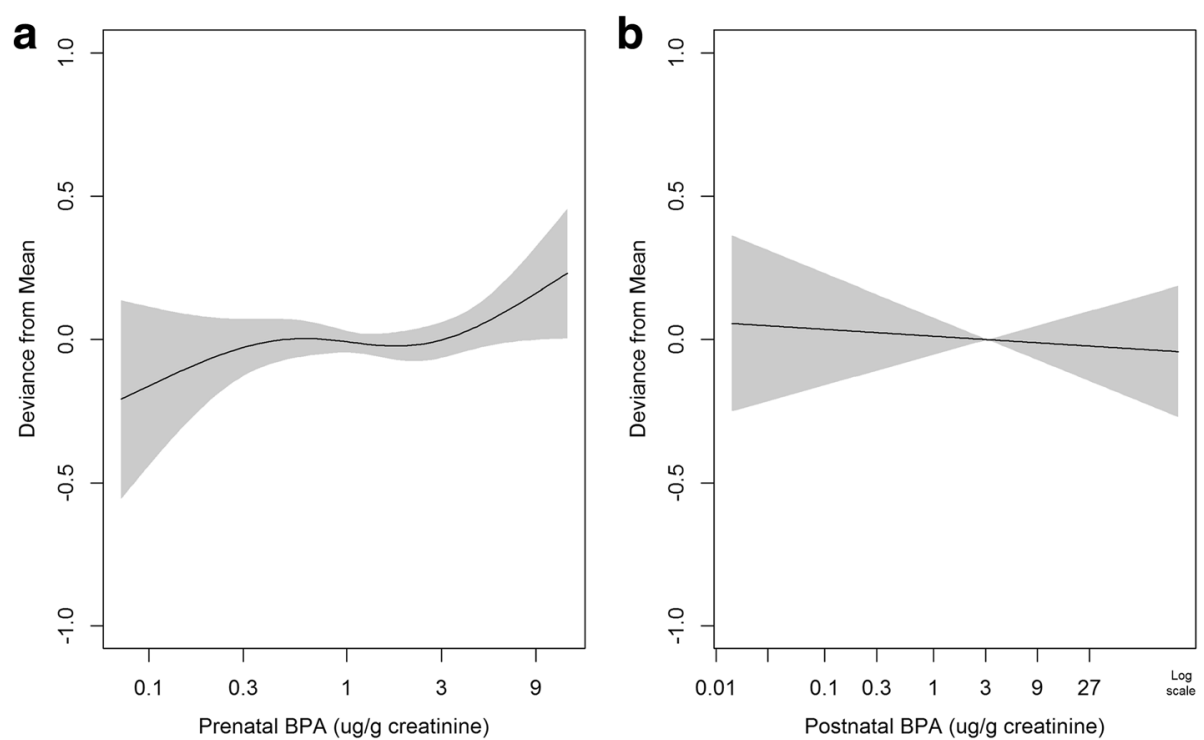

Fig. 1 Relationship between creatinine-adjusted concentrations of prenatal (a) and postnatal (b) bisphenol A (BPA) and total Korean version of the Social Communication Questionnaire (K-SCQ) scores. Models were adjusted for gender (boy or girl), parity (1st vs. other), mother's education (high school or lower vs. more than high school), birth weight (kg), and use of plastic dishes in the microwave oven (yes or no). In addition, prenatal and postnatal BPA levels were mutually controlled for in the model

not observe significant linear associations between prenatal BPA exposure and social impairments, as previously shown in Fig. 1(a). However, each doubling of postnatal exposure to BPA at 4 years of age was significantly associated with an increase in social communication of $11.8 \%$ (95\% confidence interval [CI], $0.6 \%$ to $24.3 \%)$ in girls. The effect size was significantly different in girls compared to boys $(P=0.0054)$. Our sensitivity analysis indicated that there is a similar relationship for creatinine-unadjusted postnatal BPA as for creatinineadjusted BPA (Additional file 1: Table S3). Additional adjustment for covariates did not change the main findings (Additional file 1: Table S4).

We observed a flexion point in the association curve in Fig. 1(a); therefore, we estimated the above-threshold effects of prenatal BPA on social impairments. At or

Table 3 Percentage change in scores on the K-SCQ associated with 2-fold increases in creatinine-adjusted prenatal and postnatal BPA levels

\begin{tabular}{|c|c|c|c|c|c|c|c|}
\hline \multirow[t]{2}{*}{ Subcategory of K-SCQ score } & \multirow[t]{2}{*}{ Gender } & \multicolumn{3}{|l|}{ Prenatal BPA } & \multicolumn{3}{|l|}{ Postnatal BPA } \\
\hline & & $\begin{array}{l}\% \text { change } \\
(95 \% \mathrm{Cl})\end{array}$ & $P$-value & $\begin{array}{l}P \text {-value for gender } \\
\text { difference }\end{array}$ & $\begin{array}{l}\text { \% change } \\
(95 \% \mathrm{Cl})\end{array}$ & $P$-value & $\begin{array}{l}P \text {-value for gender } \\
\text { difference }\end{array}$ \\
\hline \multirow[t]{3}{*}{$\overline{\text { Total }}$} & All & $3.4(-0.8,7.7)$ & 0.1134 & 0.2464 & $-1.0(-5.1,3.3)$ & 0.6517 & 0.0034 \\
\hline & Boys & $3.7(-1.4,9.1)$ & 0.1593 & & $-5.2(-10.3,0.1)^{\#}$ & 0.0553 & \\
\hline & Girls & $2.2(-4.6,9.4)$ & 0.5359 & & $4.5(-2.3,11.8)$ & 0.1966 & \\
\hline \multirow[t]{3}{*}{ Social interaction } & All & $-0.3(-8.1,8.1)$ & 0.9365 & 0.3835 & $-5.6(-13.1,2.5)$ & 0.1708 & 0.8667 \\
\hline & Boys & $-3.2(-12.1,6.7)$ & 0.5129 & & $-6.8(-16.4,3.8)$ & 0.2003 & \\
\hline & Girls & $7.0(-7.0,23.2)$ & 0.3434 & & $-5.7(-17.4,7.8)$ & 0.3904 & \\
\hline \multirow[t]{3}{*}{ Social communication } & All & $3.5(-3.1,10.6)$ & 0.3090 & 0.2167 & $2.0(-4.9,9.3)$ & 0.5848 & 0.0054 \\
\hline & Boys & $6.4(-2.3,15.8)$ & 0.1548 & & $-5.2(-13.5,3.9)$ & 0.2551 & \\
\hline & Girls & $-1.0(-10.8,9.9)$ & 0.8526 & & $11.8(0.6,24.3)^{*}$ & 0.0392 & \\
\hline \multirow[t]{3}{*}{ Behavior patterns } & All & $5.5(-1.9,13.5)$ & 0.1463 & 0.2075 & $-0.2(-7.5,7.6)$ & 0.9510 & 0.0374 \\
\hline & Boys & $6.0(-3.1,16.1)$ & 0.2020 & & $-4.8(-13.4,4.5)$ & 0.2999 & \\
\hline & Girls & $3.2(-8.7,16.7)$ & 0.6146 & & $5.2(-6.7,18.6)$ & 0.4102 & \\
\hline
\end{tabular}

Models were adjusted for gender (boy or girl), parity (1st vs. other), mother's education (high school or lower vs. more than high school), birth weight (kg), and use of plastic dishes in the microwave oven (yes or no). In addition, prenatal and postnatal BPA levels were mutually controlled for in the model Abbreviations: $K-S C Q$ Korean version of the Social Communication Questionnaire, BPA bisphenol A, $\mathrm{Cl}$ confidence interval ${ }^{*} P$-value $<0.05$; ${ }^{\#}$-value $<0.1$ 
above the threshold $(3.0 \mu \mathrm{g} / \mathrm{g}$ creatinine of BPA), the total scores of all participants increased by $16.9 \%$ (95\% $\mathrm{CI}, 2.3 \%$ to $33.5 \%$ ) per 2 -fold increase in prenatal BPA. The magnitude of the increase in social communication scores associated with prenatal BPA concentrations at or above the threshold $(3.0 \mu \mathrm{g} / \mathrm{g}$ creatinine of BPA) was greater in girls than boys $(4.7 \%[95 \% \mathrm{CI},-22.4 \%$ to 41.3\%] for boys vs. $58.4 \%$ [ $95 \%$ CI, $6.5 \%$ to $135.8 \%$ ] for girls) (Table 4). This difference was marginally significant $(P$-value $<0.1)$ (Additional file 1: Figure S2). Social interaction and behavior patterns were not associated with prenatal or postnatal BPA concentrations in the total sample or for boys and girls separately.

\section{Discussion}

The present study examined the relationships between prenatal and postnatal BPA exposure, and social impairments in 4-year-old children; we found that prenatal exposure to BPA at or above $3.0 \mu \mathrm{g} / \mathrm{g}$ creatinine and postnatal exposure to BPA at 4 years of age were significantly associated with social communication impairments in girls, as measured by the K-SCQ.

Exposure to endocrine-disrupting chemicals with estrogenic activity can alter brain and behavioral development during critical periods of fetal development [47]. Rodent studies have demonstrated that prenatal exposure to BPA affects social behaviors, anxiety levels, and sexual differentiation in offspring $[48,49]$ through enduring transgenerational effects on vasopressin and oxytocin mRNA in the brain [50]. These hormones affect many social behaviors $[51,52]$. However, human studies have produced inconsistent results. Two studies have shown that prenatal exposure to BPA is associated with depressed behavior and anxiety in 3-year-old children [12], as well as internalizing and externalizing problems in school-aged children [16]. However, other studies have not found significant associations between prenatal exposure to BPA and social impairments [19] or autistic behaviors [20] in school-aged children.

While toxicology studies frequently assume the presence of linear relationships, this assumption may not be valid for receptor-mediated mechanisms [53]. We found that the linear association between social impairment and prenatal BPA was not statistically significant at the $\alpha=0.05$ level. However, considering the flexion point in the non-linear relationship, total K-SCQ was strongly associated with above-threshold prenatal BPA concentrations $(16.9 \%$ [95\% CI, $2.3 \%$ to $33.5 \%])$. This association was particularly strong for social communication in girls (58.4\% [95\% CI, 6.5\% to $135.8 \%]$ ). The range of BPA exposures in this study was quite narrow compared to the doses typically employed in animal neurotoxicity studies $[53,54]$. Therefore, we cannot conclude that the nonlinear relationship indicated by our study is consistent with non-linear relationships in animal neurotoxicity studies. However, the non-linear relationship is similar to the findings of other human observational studies with low-level exposure to BPA, which are comparable to the exposure level in the present study $[25,41]$. To confirm the threshold effects, further studies of the nonlinear relationships between neurobehavioral development and exposure to BPA should be conducted during the critical period, including in other geographic areas or in populations of other races or ethnicities.

Table 4 Percentage change in K-SCQ scores associated with 2-fold increases in creatinine-adjusted prenatal BPA levels above or below $3.0 \mu \mathrm{g} / \mathrm{g}$ creatinine

\begin{tabular}{|c|c|c|c|c|c|}
\hline \multirow[b]{2}{*}{ Subcategory of K-SCQ score } & \multirow[b]{2}{*}{ Gender } & \multicolumn{2}{|c|}{ Below 3.0 mg/g creatinine } & \multicolumn{2}{|c|}{ At or above $3.0 \mu \mathrm{g} / \mathrm{g}$ creatinine } \\
\hline & & $\%$ change $(95 \% \mathrm{Cl})$ & $P$-value & \% change $(95 \% \mathrm{Cl})$ & $P$-value \\
\hline \multirow[t]{3}{*}{ Total } & All & $-0.1(-4.8,4.9)$ & 0.9728 & $16.9(2.3,33.5)^{*}$ & 0.0214 \\
\hline & Boys & $1.3(-5.2,8.2)$ & 0.7062 & $10.8(-6.1,30.7)$ & 0.2248 \\
\hline & Girls & $-1.7(-8.8,6.0)$ & 0.6624 & $29.4(0.2,67.1)^{*}$ & 0.0483 \\
\hline \multirow[t]{3}{*}{ Social interaction } & All & $-1.6(-11.6,9.6)$ & 0.7707 & $11.4(-17.5,50.4)$ & 0.4817 \\
\hline & Boys & $-6.4(-18.2,7.1)$ & 0.3341 & $15.8(-18.5,64.7)$ & 0.4127 \\
\hline & Girls & $13.2(-5.7,35.8)$ & 0.1842 & $-3.4(-51.6,92.5)$ & 0.9210 \\
\hline \multirow[t]{3}{*}{ Social communication } & All & $-1.3(-9.5,7.6)$ & 0.7638 & $24.4(-1.0,56.4)^{\#}$ & 0.0610 \\
\hline & Boys & $7.0(-5.6,21.3)$ & 0.2886 & $4.7(-22.4,41.3)$ & 0.7644 \\
\hline & Girls & $-9.0(-20.0,3.5)$ & 0.1516 & $58.4(6.5,135.8)^{*}$ & 0.0233 \\
\hline \multirow[t]{3}{*}{ Behavior patterns } & All & $2.2(-7.3,12.7)$ & 0.6554 & $20.2(-7.4,55.9)$ & 0.1667 \\
\hline & Boys & $3.7(-8.9,18.1)$ & 0.5796 & $16.3(-15.0,59.2)$ & 0.3443 \\
\hline & Girls & $-0.9(-15.1,15.7)$ & 0.9080 & $29.3(-24.5,121.6)$ & 0.3488 \\
\hline
\end{tabular}

Models were adjusted for gender (boy or girl), parity (1st vs. other), mother's education (high school or lower vs. more than high school), birth weight (kg), and use of plastic dishes in the microwave oven (yes or no). In addition, prenatal and postnatal BPA levels were mutually controlled for in the model Abbreviations: $K-S C Q$ Korean version of the Social Communication Questionnaire, BPA bisphenol A, $\mathrm{Cl}$ confidence interval

${ }^{*} P$-value $<0.05 ;{ }^{\#}$-value $<0.1$ 
One previous study has evaluated the association between social impairments or autistic behavior and childhood exposure to BPA. The results of that study indicate that BPA metabolites are 2 times higher in children with ASD compared to children without ASD [55]. Our results indicate that there is a significant association between postnatal exposure to BPA and social communication, but not between BPA and other subcategories of social impairments (social interaction and behavior patterns). However, the scarcity of prior studies examining the link between BPA exposure in children and the risk of social impairments or autistic behavior, combined with the fact that the current study found a significant association only for a subtype of social impairment, necessitate additional epidemiological studies to confirm our findings.

Prenatal BPA exposure alters mRNA for the epigenetic regulators DNA methyltransferase 1 (DNMT1) and DNMT3A, as well as the brain region-specific expression of genes encoding estrogen receptors. Therefore, BPA may underlie enduring changes in brain function and behavior, especially for sexually dimorphic phenotypes [56]. However, epidemiological studies of sexspecific BPA effects on behavior have produced inconsistent results. Two previous studies found significant associations between prenatal BPA exposure and behavioral changes only in girls [12, 13]. Conversely, other studies have found significant associations between prenatal BPA and anxiety, depression, and behavioral changes in boys, but not girls [14-16, 57]. When using non-linear regression models, we observed significantly greater effects of prenatal BPA at or above the threshold level $(3.0 \mu \mathrm{g} / \mathrm{g}$ creatinine) on social communication in girls compared to boys ( $58.4 \%$ for girls vs. $4.7 \%$ for boys). Similarly, we observed a significant gender difference in the association between postnatal exposure to BPA and social communication. Further studies may be required to address the differential mechanisms for the effects of exposure to BPA on neurobehavioral development in boys compared to girls.

Although the cohort design of this study is a strength, our study also had some limitations. First, the K-SCQ was used as a screening tool to detect social impairments in children. As this test was completed by parents or caregivers, its results may have been influenced by observer bias. Furthermore, none of the children in the current study had severe social impairments at 4 years of age. Parents or caregivers may over- or under-report their children's symptoms, which may result in misclassification on the K-SCQ and null associations. Given this limitation, the present study conservatively estimated the effects of prenatal and postnatal BPA exposure and found significant associations between BPA exposure and social impairment at 4 years of age. Second, we collected spot urine samples from pregnant women and their children. Given that the half-life of BPA is approximately $6 \mathrm{~h}$, the spot urine samples may not have captured intra-individual variability in BPA metabolism over time; however, Ye et al. propose that spot urine samples reflect the average exposure of a population to BPA [58]. We collected urine samples in the morning to eliminate within-day variations, although unmeasured variation may still exist. Third, since social skills in children may progress as they develop, caution should be exercised in the interpretation of the results obtained at 4 years of age, as social communication skills have not matured. Finally, we did not investigate the potential for reverse causality of the association between postnatal BPA and social impairments. Children with more behavior problems may have different dietary or mouthing behavior $[59,60]$ that may increase their BPA exposure.

\section{Conclusions}

The prospective cohort study design is a strength of this study investigating the relationships between prenatal and postnatal BPA concentrations and social impairments at 4 years of age. Although the study has several limitations, including parent-reported questionnaires to evaluate social impairments and no participants with severe social impairments, the study makes a significant contribution to research on endocrine disruptors' impact on children health because the relationship between BPA exposure and neurodevelopmental effects has not been fully elucidated in humans, and our results elucidate BPA exposure effects related to social impairments. Specifically, prenatal BPA exposure was significantly associated with impairments at or above the flexion point of $3.0 \mu \mathrm{g} / \mathrm{g}$ creatinine, whereas there was a linear association for postnatal BPA exposure. Further studies to evaluate the health implications and underlying mechanisms of these findings are warranted.

\section{Additional file}

Additional file 1: Figure S1. Selection of study participants. Table S1.
Characteristics of mothers included and excluded in the follow-up of the
Birth cohort ( $N=10,752)$. Table S2. Characteristics of participants included
and excluded in the study. Table S3. Percentage change in scores on the
K-SCQ associated with 2-fold increase in creatinine-unadjusted prenatal and
postnatal BPA levels. Table S4. Percentage change in scores on the K-SCQ
associated with 2-fold increase in creatinine-adjusted prenatal and postnatal
BPA levels after controlling for covariates. Figure S2. Percentage change in
scores on the K-SCQ associated with 2-fold increase at or above level of
creatinine-adjusted prenatal Bisphenol A ( 3.0 Hg/g creatinine) by sex.
(DOCX $143 \mathrm{~kb}$ )

\section{Abbreviations}

ASD: Autism spectrum disorder; BMI: Body mass index; BPA: Bisphenol A; DNMT: DNA methyltransferase; EDC: Environment and Development of Children; K-SCQ: Korean version of the Social Communication Questionnaire; LOD: Lower limit of detection 


\section{Acknowledgements}

The authors thank Jin-A Park, Ji-Young Lee, and Yumi Choi for their assistance with data collection.

\section{Funding}

This study was partially supported by grants from the Environmental Health Center funded by the Korean Ministry of Environment, an R\&D Research program funded by the Ministry of Food and Drug Safety of Korea, and the Women Scientist Research Program through the National Research Foundation of Korea, which is funded by the Ministry of Science, ICT, and Future Planning of Korea (\#2015R1A1A3A04001325).

\section{Availability of data and materials}

Please contact the corresponding author for data requests.

\section{Authors' contributions}

YHL analyzed the data and wrote the manuscript. YCH designed the study and wrote the manuscript. BNK, SB, YAL, JIK, and CHS performed the psychological and medical examinations and revised the manuscript. All authors read and approved the final manuscript.

\section{Ethics approval and consent to participate}

We obtained informed consent from all participants and the study protocol was approved by the Institutional Review Board at the College of Medicine, Seoul National University (IRB No. 1201-010-392).

\section{Consent for publication}

Not applicable.

\section{Competing interests}

The authors declare that they have no competing interests.

\section{Publisher's Note}

Springer Nature remains neutral with regard to jurisdictional claims in published maps and institutional affiliations.

\section{Author details}

${ }^{1}$ Institute of Environmental Medicine, Seoul National University Medical Research Center, Seoul, Republic of Korea. ${ }^{2}$ Environmental Health Center Seoul National University College of Medicine, Seoul, Republic of Korea. ${ }^{3}$ Department of Preventive Medicine, Dankook University, Cheonan, Republic of Korea. ${ }^{4}$ Division of Children and Adolescent Psychiatry, Department of Psychiatry, Seoul National University Hospital, Seoul, Republic of Korea. ${ }^{5}$ Department of Pediatrics, Seoul National University Children's Hospital, Seoul, Republic of Korea. ${ }^{6}$ Department of Preventive Medicine, Seoul National University College of Medicine, Seoul, Republic of Korea.

Received: 16 January 2017 Accepted: 18 July 2017

Published online: 26 July 2017

\section{References}

1. Calafat AM, Kuklenyik Z, Reidy JA, Caudill SP, Ekong J, Needham LL. Urinary concentrations of bisphenol $A$ and 4-nonylphenol in a human reference population. Environ Health Perspect. 2005;113(4):391-5.

2. Woodruff TJ, Zota AR, Schwartz JM. Environmental chemicals in pregnant women in the United States: NHANES 2003-2004. Environ Health Perspect. 2011;119(6):878.

3. Covaci A, Hond ED, Geens T, Govarts E, Koppen G, Frederiksen H, Knudsen LE, Mørck TA, Gutleb AC, Guignard C, et al. Urinary BPA measurements in children and mothers from six European member states: overall results and determinants of exposure. Environ Res. 2015;141:77-85.

4. Geens T, Aerts D, Berthot C, Bourguignon J-P, Goeyens L, Lecomte $P$, Maghuin-Rogister G, Pironnet A-M, Pussemier L, Scippo M-L. A review of dietary and non-dietary exposure to bisphenol-A. Food Chem Toxicol. 2012; 50(10):3725-40.

5. Ye X, Pierik FH, Angerer J, Meltzer HM, Jaddoe WW, Tiemeier H, Hoppin JA, Longnecker MP. Levels of metabolites of organophosphate pesticides, phthalates, and bisphenol a in pooled urine specimens from pregnant women participating in the Norwegian Mother and Child Cohort Study (MoBa). Int J Hyg Environ Health. 2009;212(5):481-91.
6. Becker K, Güen T, Seiwert M, Conrad A, Pick-Fuß H, Müller J, Wittassek M, Schulz C, Kolossa-Gehring M. GerES IV: phthalate metabolites and bisphenol A in urine of German children. Int J Hyg Environ Health. 2009:212(6):685-92.

7. Ye X, Pierik FH, Hauser R, Duty S, Angerer J, Park MM, Burdorf A, Hofman A, Jaddoe WW, Mackenbach JP, et al. Urinary metabolite concentrations of organophosphorous pesticides, bisphenol A, and phthalates among pregnant women in Rotterdam, the Netherlands: the Generation R Study. Environ Res. 2008;108(2):260-7.

8. Teitelbaum S, Britton J, Calafat A, Ye X, Silva M, Reidy J, Galvez M, Brenner B, Wolff $M$. Temporal variability in urinary concentrations of phthalate metabolites, phytoestrogens and phenols among minority children in the United States. Environ Res. 2008;106(2):257-69.

9. Calafat AM, Needham LL. Factors affecting the evaluation of biomonitoring data for human exposure assessment. Int J Androl. 2008;31(2):139-43.

10. Wolff MS, Engel SM, Berkowitz GS, Ye X, Silva MJ, Zhu C, Wetmur J, Calafat AM. Prenatal phenol and phthalate exposures and birth outcomes. Environ Health Perspect. 2008;116(8):1092-7.

11. Liu Z, Wolff MS, Moline J. Analysis of environmental biomarkers in urine using an electrochemical detector. J Chromatogr B. 2005;819(1):155-9.

12. Braun JM, Kalkbrenner AE, Calafat AM, Yolton $K$, Ye X, Dietrich KN, Lanphear BP. Impact of early-life bisphenol A exposure on behavior and executive function in children. Pediatrics. 2011;128(5):873-82.

13. Braun JM, Yolton K, Dietrich KN, Hornung R, Ye X, Calafat AM, Lanphear BP. Prenatal bisphenol A exposure and early childhood behavior. Environ Health Perspect. 2009;117(12):1945-52.

14. Perera F, Vishnevetsky J, Herbstman JB, Calafat AM, Xiong W, Rauh V, Wang S. Prenatal bisphenol A exposure and child behavior in an inner-city cohort. Environ Health Perspect. 2012;120(8):1190-4.

15. Roen EL, Wang Y, Calafat AM, Wang S, Margolis A, Herbstman J, Hoepner LA, Rauh V, Perera FP. Bisphenol A exposure and behavioral problems among inner city children at 7-9 years of age. Environ Res. 2015;142:739-45.

16. Harley KG, Gunier RB, Kogut K, Johnson C, Bradman A, Calafat AM, Eskenazi B. Prenatal and early childhood bisphenol A concentrations and behavior in school-aged children. Environ Res. 2013;126:43-50.

17. Wolstenholme JT, Goldsby JA, Rissman EF. Transgenerational effects of prenatal bisphenol A on social recognition. Horm Behav. 2013;64(5):833-9.

18. Palanza P, Gioiosa L, vom Saal FS, Parmigiani S. Effects of developmental exposure to bisphenol A on brain and behavior in mice. Environ Res. 2008; 108(2):150-7.

19. Miodovnik A, Engel SM, Zhu C, Ye X, Soorya LV, Silva MJ, Calafat AM, Wolff MS. Endocrine disruptors and childhood social impairment. Neurotoxicology. 2011;32(2):261-7.

20. Braun JM, Kalkbrenner AE, Just AC, Yolton K, Calafat AM, Sjodin A, Hauser R, Webster GM, Chen A, Lanphear BP. Gestational exposure to endocrinedisrupting chemicals and reciprocal social, repetitive, and stereotypic behaviors in 4- and 5-year-old children: the HOME study. Environ Health Perspect. 2014;122(5):513-20

21. Bellanger M, Demeneix B, Grandjean P, Zoeller RT, Trasande L. Neurobehavioral deficits, diseases, and associated costs of exposure to endocrine-disrupting chemicals in the European Union. J Clin Endocrinol Metab. 2015;100(4):1256-66.

22. EFSA explains the safety of bisphenol A. Scientific opinion on bisphenol A. http://www.efsa.europa.eu/sites/default/files/corporate_publications/files/ factsheetbpa150121.pdf. Accessed 25 June 2017.

23. Vom Saal FS, Sheehan DM: Challenging risk assessment. In: Forum for applied research and public policy. Knoxville. 1998;13(3):11-18.

24. Xu X-h, Zhang J, Wang Y-m, Ye Y-p, Luo Q-q. Perinatal exposure to bisphenol-A impairs learning-memory by concomitant down-regulation of $\mathrm{N}$-methyl-D-aspartate receptors of hippocampus in male offspring mice. Horm Behav. 2010;58(2):326-33.

25. Hong S-B, Hong Y-C, Kim J-W, Park E-J, Shin M-S, Kim B-N, Yoo H-J, Cho I-H, Bhang S-Y, Cho S-C. Bisphenol A in relation to behavior and learning of school-age children. J Child Psychol Psychiatry. 2013;54(8):890-9.

26. Vandenberg LN, Colborn T, Hayes TB, Heindel JJ, Jacobs DR Jr, Lee D-H, Shioda T, Soto AM, vom Saal FS, Welshons WV. Hormones and endocrinedisrupting chemicals: low-dose effects and nonmonotonic dose responses. Endocr Rev, 2012:33(3):378-455.

27. Vandenberg LN, Hunt PA, Myers JP, vom Saal FS. Human exposures to bisphenol A: mismatches between data and assumptions. Rev Environ Health. 2013;28(1):37-58. 
28. Gioiosa L, Fissore E, Ghirardelli G, Parmigiani S, Palanza P. Developmental exposure to low-dose estrogenic endocrine disruptors alters sex differences in exploration and emotional responses in mice. Horm Behav. 2007;52(3): 307-16.

29. Gioiosa L, Parmigiani S, vom Saal FS, Palanza P. The effects of bisphenol A on emotional behavior depend upon the timing of exposure, age and gender in mice. Horm Behav. 2013;63(4):598-605.

30. Jašarević E, Sieli PT, Twellman EE, Welsh TH, Schachtman TR, Roberts RM, Geary DC, Rosenfeld CS. Disruption of adult expression of sexually selected traits by developmental exposure to bisphenol A. Proc Natl Acad Sci. 2011; 108(28):11715-20

31. Palanza PL, Howdeshell KL, Parmigiani S, vom Saal FS. Exposure to a low dose of bisphenol A during fetal life or in adulthood alters maternal behavior in mice. Environ Health Perspect. 2002;110(Suppl 3):415.

32. Palanza P, Nagel SC, Parmigiani S, vom Saal FS. Perinatal exposure to endocrine disruptors: sex, timing and behavioral endpoints. Curr Opin Behav Sci. 2016;7:69-75.

33. Trasande L, Attina TM, Blustein J. Association between urinary bisphenol A concentration and obesity prevalence in children and adolescents. JAMA. 2012;308(11):1113-21.

34. Cho MJ, Kim KH. Use of the center for epidemiologic studies depression (CES-D) scale in Korea. J Nerv Ment Dis. 1998;186(5):304-10.

35. Lim Y, Oh SY. Development of a semi-quantitative food frequency questionnaire for pre-school children in Korea. Korean J Community Nutr. 2002;7(1):58-66.

36. Kim JH, Sunwoo HJ, Park SB, Noh DH, Jung YK, Cho IH, Cho SC, Kim BN, Shin MS, Kim JW. A validation study of the Korean version of social communication questionnaire. J Korean Acad Child Adolesc Psychiatry. 2015;26(3):197-208.

37. Chandler S, Charman T, Baird G, Simonoff E, Loucas T, Meldrum D, Scott M Pickles A. Validation of the social communication questionnaire in a population cohort of children with autism spectrum disorders. J Am Acad Child Adolesc Psychiatry. 2007;46(10):1324-32.

38. Rutter M, Bailey A, Lord C. In: Services WP, editor. Social Communication Questionnaire (SCQ). Los Angeles: Western Psychological Services; 2003.

39. Yang M, Kim S-Y, Lee S-M, Chang S-S, Kawamoto T, Jang J-Y, Ahn Y-O. Biological monitoring of bisphenol $\mathrm{A}$ in a Korean population. Arch Environ Contam Toxicol. 2003:44(4):546-51.

40. Bae S, Kim JH, Lim Y-H, Park HY, Hong Y-C. Associations of bisphenol A exposure with heart rate variability and blood pressure. Hypertension. 2012; 60(3):786-93.

41. Bae $\mathrm{S}$, Lim Y-H, Lee YA, Shin CH, Oh S-Y, Hong Y-C. Maternal urinary bisphenol A concentration during midterm pregnancy and children's blood pressure at age 4. Hypertension. 2016;69(2):367-74.

42. Akaike $\mathrm{H}$. A new look at the statistical model identification. IEEE Trans Autom Control. 1974;19(6):716-23.

43. Vandenberg LN, Maffini MV, Sonnenschein C, Rubin BS, Soto AM. Bisphenol$A$ and the great divide: a review of controversies in the field of endocrine disruption. Endocr Rev. 2009:30(1):75-95.

44. HEAT: Health Effects of Air pollution and Temperature. http://CRAN.Rproject.org/package=HEAT. Accessed 25 June 2017.

45. Lim Y-H, Park M-S, Kim Y, Kim H, Hong Y-C. Effects of cold and hot temperature on dehydration: a mechanism of cardiovascular burden. Int J Biometeorol. 2015;59(8):1035-43.

46. Bae S, Lim Y-H, Kashima S, Yorifuji T, Honda Y, Kim H, Hong Y-C. Non-linear concentration-response relationships between ambient ozone and daily mortality. PLoS One. 2015:10(6):e0129423.

47. Palanza P, Morellini F, Parmigiani S, Vom Saal F. Prenatal exposure to endocrine disrupting chemicals: effects on behavioral development. Neurosci Biobehav Rev. 1999;23(7):1011-27.

48. Cox KH, Gatewood JD, Howeth C, Rissman EF. Gestational exposure to bisphenol $\mathrm{A}$ and cross-fostering affect behaviors in juvenile mice. Horm Behav. 2010;58(5):754-61.

49. Wolstenholme JT, Taylor JA, Shetty S, Edwards M, Connelly JJ, Rissman EF. Gestational exposure to low dose bisphenol A alters social behavior in juvenile mice. PLoS One. 2011;6(9):e25448.

50. Wolstenholme JT, Edwards M, Shetty SR, Gatewood JD, Taylor JA, Rissman $\mathrm{EF}$, Connelly JJ. Gestational exposure to bisphenol A produces transgenerational changes in behaviors and gene expression. Endocrinology. 2012;153(8):3828-38.
51. Shepard KN, Michopoulos V, Toufexis DJ, Wilson ME. Genetic, epigenetic and environmental impact on sex differences in social behavior. Physiol Behav. 2009;97(2):157-70.

52. Veenema $A H$, Neumann ID. Central vasopressin and oxytocin release: regulation of complex social behaviours. Prog Brain Res. 2008;170:261-76.

53. Welshons WV, Thayer KA, Judy BM, Taylor JA, Curran EM, Vom Saal FS. Large effects from small exposures. I. Mechanisms for endocrine-disrupting chemicals with estrogenic activity. Environ Health Perspect. 2003;111(8):994.

54. Integrated Risk Information System (IRIS) Bisphenol A. https://cfpub.epa.gov/ ncea/iris2/chemicalLanding.cfm?substance_nmbr=356. Accessed 25 June 2017

55. Stein TP, Schluter MD, Steer RA, Guo L, Ming X. Bisphenol A exposure in children with autism spectrum disorders. Autism Res. 2015;8(3):272-83.

56. Kundakovic M, Gudsnuk K, Franks B, Madrid J, Miller RL, Perera FP, Champagne FA. Sex-specific epigenetic disruption and behavioral changes following low-dose in utero bisphenol A exposure. Proc Natl Acad Sci. 2013, 110(24):9956-61.

57. Evans SF, Kobrosly RW, Barrett ES, Thurston SW, Calafat AM, Weiss B, Stahlhut R, Yolton K, Swan SH. Prenatal bisphenol A exposure and maternally reported behavior in boys and girls. Neurotoxicology. 2014;45:91-9.

58. Ye $X$, Wong L-Y, Bishop AM, Calafat AM. Variability of urinary concentrations of bisphenol $A$ in spot samples, first morning voids, and 24-hour collections. Environ Health Perspect. 2011;119(7):983.

59. Cermak SA, Curtin C, Bandini LG. Food selectivity and sensory sensitivity in children with autism spectrum disorders. J Am Diet Assoc. 2010;110(2):238-46.

60. Goh HL, Iwata BA, Shore BA, DeLeon IG, Lerman DC, Ulrich SM, Smith RG. An analysis of the reinforcing properties of hand mouthing. J Appl Behav Anal. 1995:28(3):269-83.

\section{Submit your next manuscript to BioMed Central and we will help you at every step:}

- We accept pre-submission inquiries

- Our selector tool helps you to find the most relevant journal

- We provide round the clock customer support

- Convenient online submission

- Thorough peer review

- Inclusion in PubMed and all major indexing services

- Maximum visibility for your research

Submit your manuscript at www.biomedcentral.com/submit 